\title{
Colonoscopic assessment of large bowel diseases and its effectiveness
}

\author{
Degaonkar A.S. ${ }^{1}$, Bhalge S.D. ${ }^{2}$, Chavan Aashish R. ${ }^{3}$ \\ ${ }^{1}$ Dr. Anil S. Degaonkar, Associate Professor, ${ }^{2}$ Dr. Shivcharan D. Bhalge, Assistant Professor, Department of Surgery, \\ ${ }^{3}$ Dr. Aashish R. Chavan, Assistant Professor, Department of Surgery; all authors are affiliated with Dr. Shankarrao \\ Chavan Government Medical College, Vishnupuri, Nanded, Maharashtra, India.
}

Corresponding Author: Dr. Shivcharan D. Bhalge, Department of General Surgery Dr. Shankarrao Chavan Government Medical College, Vishnupuri, Nanded, Maharashtra, India. Email: dr.shivcharanbhalge@gmail.com

\begin{abstract}
Introduction: Colonoscopy, for any suspected colonic disease is the first line of investigation. The spectrum of colonic diseases varies from benign to malignant lesions, of which the incidence and mortality differ across the world due to differences in risk factors. Colonoscopy is carried out for diagnostic and/or therapeutic purposes. Materials and Methods: It was a hospital based cross sectional study conducted in Dr. Shankarrao Chavan Govt. Medical College, Nanded, during study period of May 2016 to December 2017 on 104 patients presented with clinical features of large bowel diseases. Results: The mean age of the patients was $45.59 \pm 18.46$ years (range $5-95$ ). Males constituted $64.4 \%$ patients while females were $35.6 \%$. On colonoscopy most common suspected diagnosis was carcinoma rectum (45.3\%), followed by inflammatory bowel disease (26.7\%) and rectal polyp (12\%). Most of the lesions were found overall in rectum (49.5\%) followed by sigmoid colon (16.8\%) and caecum (12.6\%). Conclusion: Colonoscopy is a safe and simple procedure helps in locating various lesions in the entire colon and confirming the diagnosis by histopathology. Colonoscopy helps not only in the diagnosis but also in the treatment and follow up of the patient especially in the colonic diseases like colonic cancer and inflammatory bowel diseases.
\end{abstract}

Key words: Colonoscopy, Colorectal Cancer, IBD, Polyp, Large bowel disease

\section{Introduction}

Colon is the site for various benign and malignant lesions and is associated with wide spectrum of signs and symptoms. The patients usually present with complaints of chronic abdominal pain, anaemia, altered bowel habits including chronic constipation and diarrhoea, flatulence, unexplained weight loss and blood and mucus in the stools [1].

These symptoms call for investigations in the form of colonoscopy to rule out of variety of colonic diseases encompassing several acute and chronic conditions such as infections, congenital diseases, inflammatory bowel diseases, polyps, diverticulosis, vascular diseases and colonic tumours [2]. Colorectal cancer is the overall 3rd most common cancer worldwide and 4th most common cause of death [3]. In India, the overall incidence of ulcerative colitis and crohn's disease was 44.3 and 6.02 per 100,000 patients [4]. The prevalence of diverticulosis is very low in India and in western society

Manuscript Received: $10^{\text {th }}$ December 2018

Reviewed: $20^{\text {th }}$ December 2018

Author Corrected: $28^{\text {th }}$ December 2018

Accepted for Publication: 31 ${ }^{\text {st }}$ December 2018 its prevalence increases with age from $5 \%$ by age of 40 years to $65 \%$ at 80 years of age [5]. Colonic polyp occurs in younger population and its prevalence found to be about $2 \%$ in India [6]. Development of flexible sigmoidoscopy and colonoscopy has revolutionized the overall management of colonic diseases that is because colonoscopy is highly sensitive and specific procedure and is relatively safe with lower incidence of serious complications $[7,8]$.

Colonoscopy has been available since 1970's and has become an integral part in the diagnosis and treatment of colorectal diseases. It allows direct visual examination of the entire length of the colon including the distal ileum and mucosal biopsy evaluation of all the portions of colon and rectum [9]. Colonoscopy has various applications as a diagnostic, therapeutic and screening tool for wide variety of lower gastrointestinal diseases [10]. It is indicated for the diagnostic evaluation of signs and symptoms of various colonic diseases and to evaluate abnormal radiographic findings, for therapeutic interventions which includes 


\section{Original Research Article}

foreign body removal, polypectomy, stricture dilatation, colonic decompression, treatment of bleeding lesion and stent placement [11]. It is also used as screening tool to identification and removal of precancerous and cancerous lesions or polyp in the colon and rectum to reduce the incidence and mortality associated with colorectal cancers. It is considered the gold standard for cancer surveillance [12].

Due to its relatively low incremental cost, colonoscopy represents a cost effective means for detection of colorectal lesions [13]. The entire length of colon is now routinely accessible to high resolution viewing with photography of desired lesions, polypectomy, biopsy and brush cytology [14]. This study was undertaken to assess the effectiveness of colonoscopy in diagnosing the various conditions affecting the lower gastrointestinal tract in a group of patients with a wide spectrum of gastrointestinal symptoms. Other purpose was to correlate the histopathological pattern of colonic mucosal biopsies with the clinical findings.

\section{Aim and Objectives}

Aim: Colonoscopic assessment of large bowel diseases and its effectiveness.

\section{Objectives}

1. To assess various large bowel diseases by colonoscopy.

2. Age and sex-wise distribution of lesion in large bowel.

3. Site-wise distribution of lesion in large bowel.

4. To characterise colonoscopic and histopathological findings.

5. To evaluate incidence of complications for diagnostic colonoscopy.

\section{Methods and Materials}

Study design: Prospective cross sectional study

Study setting: Department of Surgery, Dr. Shankarrao Chavan Government Medical College, Nanded.

\section{Inclusion criteria}

All patients of either gender, males and females presenting to the general surgery OPD and ward with lower gastrointestinal complaints as follows were included in the study.

- Altered bowel habits (chronic constipation and chronic diarrhoea)

- Chronic abdominal pain

- Blood and mucous in stool
- Anaemia

- Lump in abdomen if ultrasound abdomen suggestive of colonic origin.

\section{Exclusion criteria}

a) Patients who are unable to communicate or unwilling to participate

b) Patients who are hemodynamically unstable, $\mathrm{BP}<90$ $\mathrm{mmHg}, \mathrm{HR}>110$ beats/min

c) Patients with bleeding disorders or coagulopathy

d) Pregnant females

Participants: The present study was carried out on indoor patients of General Surgery ward of Dr. Shankarrao Chavan Government Medical College, Nanded. The patients were recruited consecutively into the study.

Time frame to address the study: From May 2016December 2017

Sample size: Calculation of sample size was not possible as the prevalence of gastrointestinal diseases as one entity is not described. Prevalence of individual gastrointestinal disease for e.g. inflammatory bowel disease, colonic polyp, colonic cancer is available. As our study includes assessment of several lower bowel diseases, calculating sample size based on one disease specific prevalence rate is not correct. Hence, participants were recruited as when they presented to the respective OPD and ward during the period May 2016 - December 2017.At the end of study period, 104 patients were enrolled in the study.

Methodology: The study was conducted after obtaining approval from the institutional ethics committee and by abiding the rules and regulations as per Helsinki Declaration.

The investigator visited the general surgery OPD and ward. Patients with specific complaints of altered bowel habits, chronic abdominal pain, blood and mucous in stool, anaemia and lump in abdomen suggestive of colonic origin on ultrasound were recruited in the study. All the patients participating in the study were explained about the nature and purpose of the study in the language they better understand. Before including them in the study, written informed consent was obtained. Once patient enrolled into the study, detailed history of patients taken with regards to symptoms, their duration and severity, drug history, bleeding disorders. History of alcohol and smoking, radiation and blood transfusion was collected. Thorough general physical 


\section{Original Research Article}

and systemic examinations were performed. Routine haematological, biochemistry, coagulation profile and was done. If necessary Radiological investigations in the form of X-ray, ultrasound of abdomen and CECT $(\mathrm{A}+\mathrm{P})$ was done and provisional diagnosis was made. Patients scheduled for colonoscopy were explained in details regarding need, procedure and complications related to colonoscopy. Pre-anaesthetic evaluation was done.

Written informed consent with regards to procedure was taken. Bowel preparation was given with cathartic like sodium sulphate ( 2 bottles of $45 \mathrm{ml}$ in a box) mixed in $300 \mathrm{ml}$ of lime juice or limca over half an hour, followed by several glasses of water for 6-8 hours before procedure. Patient was instructed that he/she may have loose stools and nausea for which antiemetic's and IV hydration was given. Patients were subjected to video colonoscopy. Colonoscopic diagnosis was made after visualization of entire colon and diagnostic biopsy of any suspicious lesion was taken and sent for histopathology. Observations were tabulated and conclusions were drawn.

Statistical Methods: Data was entered in a Microsoft excel sheet and was analysed using SPSS version 21 software.

\section{Results}

Table-1: Demographic Variables of study subject.

\begin{tabular}{|c|c|c|c|c|c|}
\hline Age (in years) & Frequency & Percentage & Gender & Frequency & Percentage \\
\hline$<10$ & 4 & 3.8 & Male & 67 & 64.4 \\
\hline $11-20$ & 6 & 5.8 & Female & 37 & 35.6 \\
\hline $21-30$ & 13 & 12.5 & Total & 104 & 100.00 \\
\hline $31-40$ & 17 & 16.3 & & & \\
\hline $41-50$ & 23 & 22.1 & & & \\
\hline $51-60$ & 17 & 16.3 & & & \\
\hline $61-70$ & 19 & 18.3 & & & \\
\hline $71-80$ & 4 & 3.8 & & & \\
\hline$>81$ & 1 & 1 & & & \\
\hline Total & 104 & 100.00 & & & \\
\hline
\end{tabular}

Patients evaluated belonged majority in the age group of 41-50 years (22.1\%) followed by those in the age group of 61 70 years (18.3\%). Among these patients, males constituted $64.4 \%$ patients while females were 35.6

Table-2: Distribution of presenting symptoms.

\begin{tabular}{|l|c|c|}
\hline Symptoms & Frequency* & Percentage* \\
\hline Pain in abdomen & 64 & 61.5 \\
\hline Blood in stool & 49 & 47.1 \\
\hline Constipation & 15 & 14.4 \\
\hline Stoma Evaluation & 10 & 9.6 \\
\hline Mucous in stool & 9 & 8.7 \\
\hline Loose Stool & 8 & 7.7 \\
\hline Abdominal distension & 6 & 5.8 \\
\hline Fever & 4 & 3.8 \\
\hline Lump in abdomen & 4 & 3.8 \\
\hline Vomiting & 3 & 2.9 \\
\hline Weight loss & 3 & 2.9 \\
\hline Loss of appetite & 2 & 1.9 \\
\hline Perianal growth & 1 & 1 \\
\hline Blackish oral cavity & 1 & 1 \\
\hline
\end{tabular}

*values are mutually exclusive of each other. 
Majority of the patients presented with symptom of pain in abdomen (61.5\%) followed by blood in stool (47.1\%) and constipation $(14.4 \%)$.

Table-3: Distribution of colonoscopic findings.

\begin{tabular}{|c|c|c|}
\hline Findings & Frequency & Percentage \\
\hline Growth & 36 & 38.3 \\
\hline Normal study & 24 & 25.5 \\
\hline Ulcer & 23 & 24.5 \\
\hline Polyp & 10 & 10.6 \\
\hline Stenosis & 1 & 1.1 \\
\hline Total & $\mathbf{9 4}$ & $\mathbf{1 0 0 . 0 0}$ \\
\hline
\end{tabular}

On colonoscopy, majority of the patients showed the presence of growth (38.3\%) and ulcer (24.5\%). The colonoscopy was normal (25.5\%). $10.6 \%$ of the patients showed polyp while $1.1 \%$ showed stenosis.

Table-4: Distribution of lesions in colon.

\begin{tabular}{|c|c|c|}
\hline Site of lesion & Frequency* $^{*}$ & Percentage* $^{*}$ \\
\hline Rectum & 47 & 17 \\
\hline Sigmoid colon & 16 & 10.6 \\
\hline Descending colon & 10 & 1.1 \\
\hline Splenic flexure & 1 & 11.7 \\
\hline Transverse colon & 11 & 7.4 \\
\hline Ascending colon & 7 & 12.8 \\
\hline Caecum & 12 & 2.1 \\
\hline Anal canal & 2 & 1.1 \\
\hline Terminal ileum & 1 & 17 \\
\hline
\end{tabular}

*Values are mutually exclusive of each other

On colonoscopy, majority of the lesions were found in rectum (50\%) followed by sigmoid colon (17\%) and caecum $(12.8 \%)$.

Table-5: Distribution of significant lesion according to site of lesion.

\begin{tabular}{|c|c|c|c|}
\hline Part of colon & Growth & Ulcer & Polyp \\
\hline Rectum & 23 & 15 & - \\
\hline Sigmoid colon & 5 & 9 & 1 \\
\hline Descending colon & - & - & - \\
\hline Splenic flexure & 1 & 10 & 1 \\
\hline Transverse colon & - & 5 & 1 \\
\hline Ascending colon & 1 & 5 & - \\
\hline Caecum & 7 & - & - \\
\hline Anal canal & 2 & 1 & - \\
\hline Terminal ileum & - & 10 & \\
\hline
\end{tabular}

Recto-sigmoid region was most common site of growth followed caecum. Ulcer most commonly seen in rectum followed by sigmoid, transverse colon, descending colon, ascending colon, caecum and terminal ileum in their decreasing order. Rectum was most common site of polyp. 
Table-6: Colonoscopic diagnosis $(n=75)$.

\begin{tabular}{|l|c|c|}
\hline Colonoscopic diagnosis & Frequency & Percentage \\
\hline Carcinoma colon & 34 & 45.3 \\
\hline Inflammatory bowel disease & 20 & 26.7 \\
\hline Colonic polyp & 9 & 12 \\
\hline Abdominal tuberculosis & 4 & 5.3 \\
\hline Haemorhoids & 3 & 4 \\
\hline Ischamic colitis & 2 & 2.7 \\
\hline Anal Pappiloma & 1 & 1.3 \\
\hline Pseudomembranous colitis & 1 & 1.3 \\
\hline P J syndrome & 1 & 1.3 \\
\hline Total & $\mathbf{7 5}$ & $\mathbf{1 0 0 . 0 0}$ \\
\hline
\end{tabular}

On colonoscopy, most suspected diagnosis were carcinoma rectum (45.3\%), followed by inflammatory bowel disease $(26.7 \%)$ and colonic polyp (12\%).

Table -7: Histopathological diagnosis $(n=72)$.

\begin{tabular}{|l|c|c|}
\hline Histopathological diagnosis & Frequency & Percentage \\
\hline Adenocarcinoma & 18 & 25 \\
\hline IBD ( Ulcerative colitis) & 15 & 11.1 \\
\hline Chronic inflammatory granulomatous lesion & 8 & 9.7 \\
\hline Juvenile polyp & 7 & 6.9 \\
\hline Mild dysplasia & 5 & 6.9 \\
\hline No e/o malignancy & 5 & 5.6 \\
\hline NSIL- Nonspecific inflammatory lesion & 4 & 4.2 \\
\hline Squamous cell carcinoma & 3 & 4.2 \\
\hline Inflammatory polyp & 3 & 1.4 \\
\hline Anal pappiloma & 1 & 1.4 \\
\hline Inflammatory myofibroblastic tumous & 1 & 1.4 \\
\hline Tubular adenoma & 1 & $\mathbf{1 . 4}$ \\
\hline No opinion possible & $\mathbf{1}$ & $\mathbf{1 0 0 . 0 0}$ \\
\hline Total & $\mathbf{7 2}$ & \\
\hline
\end{tabular}

On histopathology, most common diagnosis was adenocarcinoma (25\%), followed by ulcerative colitis (20.8\%), while no evidence of malignancy was noted in $6.9 \%$.

No complications were observed in any of the patients.

\section{Discussion}

Colonoscopy, for any suspected colonic disease is the first line of investigation. The spectrum of colonic diseases varies from benign to malignant lesions, of which the incidence and mortality differ across the world due to differences in risk factors. Colonoscopy is carried out for diagnostic and/or therapeutic purposes and for screening or surveillance of colon cancer in high risk patients as well as assessing the treatment response in patients with known large intestine diseases [10]. The colonoscopic procedure is safe and is considered as an effective means of evaluating the large intestine with very low incidence of complications like perforation and bleeding with a mortality rate of $0.007 \%$ [15].

Colonoscopy along with histopathology of tissue samples provides a precise diagnosis which can help in the overall management of patients with colonic diseases [16]. The aim of the study was to identify the colonic lesions in a group of patient presents with wide spectrum of lower gastrointestinal symptoms. 


\section{Original Research Article}

In the present study, the age distribution of patients presented to the general surgery OPD with lower gastrointestinal symptoms ranged from 5 years to 95 years with a mean age of $45.59 \pm 18.46$ years. Out of 104 patients, males constituted (64.4\%) 67/104 and the females were about $37 / 104(35.6 \%)$ of the studied population. The most commonly affected were elderly patients in the age group of 41-50 years (22.1\%) followed by those in the age group of $61-70$ years $(18.3 \%)$. The incidence increases with the age and is more common in men than women, in a study done by, Karve et al; the male to female ratio was $1.8: 1$, there was male preponderance over females [9]. Our study confirms the same. In our study the most common symptoms the patients presented with was pain in abdomen $(61.5 \%)$, blood in stool $(47.1 \%)$ followed by constipation (14.4\%), Mucous in stool (8.7\%) and loose stool $(7.7 \%)$. The least common symptoms were loss of appetite, Weight loss, lump in abdomen and fever.

These were the main indications for undergoing colonoscopy in this present study. Out of 104 patients, 10 patients had come for stoma evaluations hence were not considered in our study and the colonoscopic findings of only 94 patients were discussed. According to a cross sectional study by Befandeh and Yazdanpanah out of 2300 colonoscopies performed, the most frequent complaint was abdominal pain $(34.76 \%)$ and rectal bleeding (20.81\%) followed by diarrhoea and constipation which are consistent with results in our study [17]. In our study, the most common lesion was growth followed by ulcer and polyp, this is in contrast to the other studies. Rajbhandari et al observed nonspecific colitis $(27.7 \%)$ and polyps $(16.7 \%)$ was more frequently in their study [18].

Another study by Befandeh and Yazdanpanah found that the most common lesion was polyp (14.4\%) followed by inflammatory bowel disease (10.9\%) [17]. Main reason for variations in the spectrum of colonoscopic findings may be because of racial differences, geographical variations, lifestyle changes, behavioral, environmental and dietary factors.

In our study, we analysed the anatomic location of above mentioned lesion on colonoscopy. The availability of flexible endoscope led to an increased rate of examination and mucosal biopsy evaluation of all portions of large intestine and rectum. The rectum alone was involved in $47(50 \%)$ patients followed by sigmoid colon in 16 patients $(17 \%)$. While the cecum was involved in 12 patients $(12.8 \%)$, the transverse colon in 11 patient (11.7) and descending colon was involved in 10 patients $(10.6 \%)$. This is in agreement with the findings in a study done by Mahamoud et al and Thakeb et al where in $52.2 \%$ and $79.2 \%$ of patients respectively, had the recto-sigmoid region as the most common site involved [19][20]. The most common lesion i.e., the growth was located in rectum (23), cecum (7) and sigmoid colon (5). The ulcers were detected maximally in rectum (15). Sigmoid colon and transverse colon (11 and 10) followed by descending colon (9). And the polyps were found most commonly in rectum (9). The growth represents a colonic mass which may be cancerous in origin, was found mainly in recto-sigmoid junction was in agreement with the study by Mahamoud et al where 76 cases had colon cancer and $55 \%$ of them were detected in recto-sigmoid region [19]. Benevides et al observed that polyps are associated with lower gastrointestinal bleeding which were located in the rectum this is also observed in present study [23]. Out of 75 patients, carcinoma colon was the colonoscopic conclusion in $45.3 \%$ of cases. $26.7 \%$ of cases were diagnosed to have inflammatory bowel disease and $12 \%$ of cases to have polyp.

Following this, other diagnosis that were made on colonoscopy were abdominal tuberculosis (5.3\%), haemorrhoid (4\%), ischemic colitis $(2.7 \%)$. We know now, colonoscopy plays a crucial role in the diagnosis, follow-up and treatment especially in cases of malignancies and inflammatory bowel disease. In a study Cai et al observed that the patients who presented with symptoms of abdominal pain, constipation and diarrhoea, the incidence of colon cancer, ulcerative colitis and polyp was $57.1 \%, 42.9 \%$ and $20.8 \%$ respectively which can be very well correlated with our study as the frequency of this symptoms are higher in their study [21]. The diagnostic yield of colonoscopy was highest for the indications of adenomatous polyp, inflammatory bowel disease and colorectal cancer [12]. This could be another reason that there is an increased frequency of these condition on colonoscopy.

We know colonoscopy is considered as a gold standard for cancer surveillance and can detect advanced cancers in asymptomatic individuals. For newly diagnosed cancer patients, it is recommended to undergo frequent colonoscopies with biopsies that can help to improve the 5 year survival rates of colorectal cancers [22].

Conclusion: On the basis of study following recommendation may be considered.

1. Colonoscopy have high diagnostic yield so it should be considered early in suspected cases or diagnostic evaluation of large bowel diseases. 


\section{Original Research Article}

2. Colonoscopy should be combined with biopsy and histopathological evaluation of suspected lesion to confirm the clinical suspicion and to initiate appropriate treatment.

3. Follow up colonoscopies at frequent interval are recommended to allow objective surveillance for colorectal cancer and inflammatory bowel diseases.

4. Radiological evaluation with Ultrasound and CT scan (abdomen and pelvis) should be consider to avoid rate of negative colonoscopy.

\section{Contribution by different authors}

Study conception and design: Dr. Degaonkar A.S. Acquisition of data: Dr. Bhalge S.D. Analysis and interpretation of data: Dr. Bhalge S.D. Dr. Chavan, Drafting of manuscript: Dr. Bhalge S.D., Dr. Chavan A. R. Critical revision: Dr. Degaonkar A.S., Dr. Bhalge S.D., Dr. Chavan A.R.

What this study adds to existing knowledge: Regular colonoscopy will improve the knowledge of the various mucosal appearances also interpretation and recording of each finding is critical in initial management as well as to predict the response to treatment in future. The association between blood in stool and pain in abdomen with colorectal carcinoma depict the importance of early colonoscopy especially in elder age groups.

Conflict of interest: None declared.

Funding: Nil, Permission from IRB: Yes

\section{References}

1. Lasson A, Kilander Anders, Stitzer P. Diagnostic yield of colonoscopy based onsymptoms. Scandinavian Journal of Gastroenterology, 2008; 43 (3): 356-362. http//doi.org/10.1080/00365520701679116.

2. Abilash SC, Shreelakshmidevi S. Histopathological Interpretation of Colonic MucosalBiopsies with Clinical Correlation: A Study in a Tertiary Care Hospital Kerala. Annalsof Pathology and Laboratory medicine. 2017; 4 (5): 567-572.DOI: 10.21276/APALM.1534

3. Haggar FA, Boushey RP. Colorectal cancer epidemiology: incidence, mortality, survival, and risk factors. Clin Colon Rectal Surg. 2009 Nov; 22 (4):1917. doi: $10.1055 / \mathrm{s}-0029-1242458$.

4. Kedia S, Ahuja V. Epidemiology of Inflammatory Bowel Disease in India: The Great Shift East. Inflamm Intest Dis. 2017 Nov;2(2):102-115. doi: 10.1159/ 000465522. Epub 2017 Apr 8.
5. Kamalesh NP, Prakash K, Pramil K, et al. Prevalence and patterns of diverticulosis in patients undergoing colonoscopy in a southern Indian hospital. Indian J Gastroenterol. 2012 Dec;31(6):337-9. doi: 10.1007/s 12664- 012-0222-0. Epub 2012 Aug 17.

6. Wickramasinghe DP, Samaranayaka SF, Lakmal C, Mathotaarachchi S, Keppetiyagama C. Types and Patterns of Colonic Polyps Encountered at a Tertiary Care Center in a Developing Country in South Asia. Analytical Cellular Pathology.2014:1-4.doi: 10.1155/ $2014 / 248142$

7. Cappell MS, Friedel D. The role of sigmoidoscopy and colonoscopy in the diagnosis and management of lower gastrointestinal disorders: endoscopic findings, therapy and complication. Medical Clinics of North America 2002; 86 (6):1253-1288.https://doi.org/ 10. 1016/ S0025-7125(02)00077-9

8. Bowles R, Leicester E, Swarbrick CB, Williams C, Romaya O, Epstein: Identification and management of polyps diagnosed at colonoscopy. Gut. 2001;48 (Suppl I-034):10-14.10.1136/gut.48.supp1_1.A10PMCID:PMC 1766846

9. Karve SH, Vidya K, Shivarudrappa AS, Prakash CJ. The Spectrum of colonic lesions:A Clinico-pathological study of colonic biopsies. Indian Journal of Pathology and Oncology. 2015; 2(4):189-209. DOI: 10.5958/23946792.2015 .00018 .6

10. Rex DK, Schoenfeld PS, Cohen J, Pike IM, Adler DG. Quality indicators forcolonoscopy. Gastrointestinal Endoscopy. 2015; 81(1):31-53.doi: 10.1016/j.tgie. 2013. 02.005. doi: 10.1016/j.gie.2014.07.058. Epub 2014 Dec 2.

11. Schoenfeld PS, Cohen J. Quality indicators for colorectal cancer screening forcolonoscopy. Tech Gastrointest Endosc. 2013; 15(2):59-68.doi: 10.1016/j. tgie. 2013. 02.005. PMID: 24098071 PMCID: PMC3790322. https:// doi.org/ 10.1016/j. tgie. 2013. 02.005 .

12. Siddique I, Mohan K, Hasan F, Memon A, Patty I, Al-Nakib B. Appropriateness ofindication and diagnostic yield of colonoscopy: First report based on the 2000 guidelines of the American Society for Gastrointestinal Endoscopy. World Journal of Gastroenterology 2005; 11(44):7007-7013.doi: 10.3748/ wjg.v11.i44.7007. 


\section{Original Research Article}

13. Sonnenberg A, Delcò F, Inadomi JM. Costeffectiveness of colonoscopy in screening for colorectal cancer. Ann Intern Med. 2000 Oct 17;133(8):573-84.

14. Thomas-Gibson C, Thapar S, Shah G and Saunders B. Colonoscopy at a combined district general hospital and specialist endoscopy unit: lessons from 505 consecutive examinations. Journal of Royal Society of Medicine. 2002; 95(4): 194 - 197.PMID: 11934910

15. Fisher DA, Maple JT, Cash BD, Decker GA, Evans JA, Fanelli RD, Jain R.Complications of Colonoscopy. Gastrointestinal Endoscopy. 2011; 74(4):744-752. DOI: https://doi.org/10.1016/j.gie.2011.07.025

16. Greene FL, Livstone EM, Troncale FJ. The role of fibreoptic colonoscopy in the diagnosis of colonic and rectal diseases. Conn Med.1973; 37:439-42.

17. Bafandeh Y, Yazdanpanah F. Distribution pattern of colorectal diseases based on2300 total colonoscopies. Gastroenterology and Hepatology From Bed to Bench 2017; 10 (2): 90-96. DOI: https://doi.org/10. 22037/ ghfbb. v0i0.895.PMID:28702131.

18. Rajbhandari M, Karmacharya A, Khamal K, Dhakal P, Shreshtha R. Histomorphological profile of colonoscopic biopsies and pattern of colorectal carcinomas in Kavre district. Kathmandu University Medical Journal. 2013; 43(3):196-200.https:// doi. org/ 10.3126/kumj.v11i3.12503
19. Mahamoud G, Kabbaj N, Amrani L, Serraj I, Guedira M, Nya M, Chaoui Z, Amrani N.A Moroccan Experience with Colonoscopy - A Review of 1157 Cases. Arab Journal of Gastroenterology. 2008; 9 (3): 82-84. http://www.arabjg.eg.net/2008_part3/ article_no. 7.pdf.

20. Thakeb F, Zakaria S, Miland M, Khalil A, Hunter S and El Robby A. A review of 10 year experience with colonoscopy. In: Zakaria $\mathrm{S}$, Thakeb $\mathrm{F}$ (eds). Gastrointestina Enodscopy: An Egyptian View, (1st edn). National Library Legal Deposit. 1987; p 83-95.

21. Cai J, Yuan Z, Zhang S. Abdominal pain, diarrhoea, constipation- -which symptom ismore indispensable to have a colonoscopy? International Journal of Clinical And Experimental Pathology.2015; 8(1):938-942.

22. Birajdar PB, Thakur SS, Bafana PN. Role of colonoscopy in the management of lowergastrointestinal disorders: Diagnostic and Therapeutic. International Journal of nnovative Research in Medical Science. 2017; 2(8):1182-1190. DOI https://doi.org/ 10. 23958/ijirms/vol02-i08/16

23. Benevides GD, Marques dos santos $\mathrm{CH}$. Colonoscopy in the diagnosis of acute lower gastrointestinal bleeding. Journal of Coloproctology. 2016;36(4):185-188.https://doi.org/10.1016/j.jcol. 2016. 04.016

\section{How to cite this article?}

Degaonkar A.S, Bhalge S.D, Chavan Aashish R. Colonoscopic assessment of large bowel diseases and its effectiveness. Surgical Update: Int J surg Orthopedics.2018;4(4):169-176.doi:10.17511/ijoso.2018.i04.07. 